\title{
On the Development of Pedagogical Excellence: Prerequisites and Preconditions
}

\author{
Anatoliy Kuzminskyy* \\ Bohdan Khmelnytskyy National University, Cherkasy, Ukraine \\ *Corresponding author: ntaras7@ukr.net
}

Received September 16, 2013; Revised October 13, 2013; Accepted Month November 30, 2013

\begin{abstract}
The article focuses on those traits of a true teacher, which - if not inherent - should be fostered and acquired by the teacher themselves and will help in enhancing pedagogical excellence. The increasing role of the University teacher and the need to further improve the pedagogical skills of the University teaching corps are dictated by the general discourse of the society towards strengthening humanistic principles in inter-human relations, building civil society, and human-centered ideology. The paper details on those principles that give direction to, sustain, and renew educators on their journey toward educating their students.
\end{abstract}

Keywords: pedagogical excellence, skills, prerequisites, preconditions

Cite This Article: Anatoliy Kuzminskyy, "On the Development of Pedagogical Excellence: Prerequisites and Preconditions.” American Journal of Educational Research 1, no. 11 (2013): 456-463. doi: 10.12691/education$1-11-1$.

\section{Introduction}

Rapid and radical changes in all spheres of public life are among the most distinctive features of today's life. The same changes are typical of pedagogical science and underlying sciences. Scientific and technological progress requires a wider and deeper knowledge, expertise, and erudition. The world globalization, integrative, centripetal, and centrifugal processes, and a new philosophy of education strongly demand new approaches to an individual's education. Hence, public and personal interests in the foreseeable future will be met only by people of new formation, whose intellectual and sensual spheres are harmoniously and dichotomously developed, who would easily and freely feel a patriotic citizen of one's native country and the world, and be familiar with the achievements of national culture and the world's cultural treasury. Such a personality is capable of active functioning, full self-actualization, and changing the life for the better. Universities and University professors are called to provide and insure this ability of their graduates.

\section{Philosophy of University Teachers' Educational Excellence}

Unfortunately, nowadays the Universities do not always get the highest quality human material from comprehensive schools. The objective realities of today very often make contemporary schools unable to provide such level of training of the fundamentals of science, which would enable the post-secondary education links to fully perform their mission.

\subsection{Classical Vs Modern}

Today we can observe an increasing number of those people who are willing to deny pedagogy as a science, blaming it for all the current ills, and stating that classical pedagogical theory of J. Comenius, A. Diesterweg, D. Dewey, A. Makarenko, and V. Sukhomlynskyy has exhausted itself, got obsolete and does not meet the challenges of the time. Some simply offer to consider teaching as a far-fetched science which does not have a subject of study. Others believe that "outdated" pedagogy should be replaced with new disciplines - philosophy of education, psychology of education, etc.

Looking for new conceptual framework for the pedagogy of modern times some scholars suggest complete rejection of the traditions of education and training, the renunciation of the heritage and continuity of historical experience in this field, and the abandonment of organized systematic training of young generations. A typical example of such a nihilistic attitude to scientific pedagogy is based on a philosophical theory of post modernistic radical anti-pedagogy.

The most active representatives of this movement are A. E. Braunmuhl, H. von Schönebeck, M. Mannoni, and others. The adherents of this concept subject the historical heritage of educational theory and practice to devastating criticism and deny the need for training and education. Anti-pedagogy views educational institutions as factors of violence, oppression of man, and pedagogy - as the phenomenon of animal-style taming, training, and terror. There are calls to eliminate the general school system, remove any sexual bans and allow free sell of drugs. Some representatives of anti-pedagogy equate schools to concentration camps and prisons; they believe that young 
people may and should be educated only by street cafes, shops, neighborhood, business, and the media.

The teacher's role is unreasonably diminished by some members of the modern Ukrainian national community. G. Gorbachev in the article "Cyber-education" (the newspaper "2000", March 3, 2006) wrote: "New information technologies in the near future will change the nature of the young generation's training and education. Pedagogy and education will become remote. This approach will possibly make universities, schools, and kindergartens redundant. The computer will be able to act as a teacher". This is a striking example of teaching amateurism and mechanistic approach to upbringing, training, and education. This brings to mind the words of K. Ushynskyy: "In education everything should be based on the teacher's individuality, as an educational energy is derived only from a living source of human personality. Any statutes and programs, any artificial institutional organism, no matter how cleverly the latter has been coined, can replace a human individual in the educational process”.

It is obvious that technical teaching aids and information technology are widely implemented in the educational process and it will evolve towards individualization and differentiation. But even the most perfect machine will never be able to fully replace the teacher's living word. It is only a living being who can teach, educate, and enter a person into the society ("socialize"), and the role of technology lies in helping with that. The increasing role of the University teacher and the need to further improve the pedagogical skills of the University teaching corps are dictated by the general discourse of the society towards strengthening humanistic principles in inter-human relations, building civil society, and human-centered ideology.

With every passing day a present-day University teacher has fewer possibilities to extrapolate high school teaching methods on the university students. University professors have to thoroughly explore the roles of facilitator, tutor, and moderator. This is because the new stage of society's evolution generates a new philosophy of education that necessitates a new educational paradigm. The task of modern pedagogy, market-economy-oriented requirements to University graduates make the University teachers master new, modern, and more effective methods of training highly-skilled professionals. There are more and more mature age applicants and students in the Universities. There is a growing proportion of "second biters" there. Students are increasingly beginning to realize that their intellectual property - knowledge and skills - is a unique product allowing them to self-actualize in the labor market and adapt to its dynamics and variability. Therefore, students demand of the University staff not only to teach them well-known and tested things, but above all, to help form their competence, prepare to meet he requirements of the workplace and perform their duties, and develop independent learning skills.

Modern pedagogy identifies two paradigms of education. The first one is traditional and focused on learning; it is increasingly criticized as formal, technocratic, and lacking humaneness. The attention of the vast majority of researchers and practitioners is focused on humanistic, student-centered, and anthropocentric pedagogy, which - according to scientists - is the most adequate to the challenges of the present stage of civilization evolution. Still, some scientists and educators in their educational human-oriented philosophy see the threat of Nietzschean "bestiality", deepening of the spiritual crisis, and advocate a return to traditional Christian principles of education and the recognition of the supremacy of Christ as the initial value and the Absolute Good.

Recently, a humanitarian paradigm, based on existential psychology, has been clearly defined in the contemporary domestic and foreign pedagogy. When in knowledgeoriented paradigm the teacher acts as a translator of knowledge and the learning process manager, and in the student-oriented one the University teacher performs the role of organizer, tutor, and the assistant in the process of knowledge acquisition, then the humanitarian paradigm is the partnership of well-matched equals with the University teacher acting as a facilitator, counselor, and consultant.

The University teacher who aims at becoming a craftsman, should be aware of the characteristics of different approaches to learning, yet focus on the most promising discourse in which a person is perceived not only as an individual but also as "an open opportunity" (Jean-Paul Sartre). Here the teacher acts as a "big brother" (A. Adler), who helps younger siblings (students) without encroaching on their autonomy and choice. A skillful teacher affects students by the very fact of their (teachers'/teacher's) presence. As noted by E. Short, "no matter what we do, it is important how we do it."

Primary requirements to university graduates in today's multicultural world are given in Table 1.

Table 1. Primary requirements to university graduates

\begin{tabular}{|l|l|l|l|}
\hline Essentials & Thinking abilities & Strive at achieving success & Power of building interpersonal relations \\
\hline Knowledge & Power of concentration & Competence & Communicability \\
\hline Proficiency & Creative thinking & Strive of serving & Need of support and understanding \\
\hline Skills & Analytical skills & Vision of perspective & Attractiveness \\
\hline $\begin{array}{l}\text { Knowledge of several European } \\
\text { languages }\end{array}$ & Being conceptual & Energetic nature & Ability to be persuasive \\
\hline Computer literacy & Ability to dispatch & Endurance & Empathy \\
\hline Self0discipline & Strategic thinking & Competitiveness & Individual approach to people \\
\hline Responsibility & Systemic thinking & Ambitiousness & Ability of team-work \\
\hline Orderliness & Business thinking & Persuasion & Motivation \\
\hline High level of universal culture & Critical thinking & Mission & Optimism \\
\hline Self-education ability & & $\begin{array}{l}\text { Orientation at the achievement } \\
\text { of high results }\end{array}$ & $\begin{array}{l}\text { Ability to understand people, events and } \\
\text { situations }\end{array}$ \\
\hline & & Problem solving abilities & Ability to encourage the others \\
\hline & & Ethics & Altruism \\
\hline & & & Ability to use relationships \\
\hline
\end{tabular}


To meet the increased demands of the students who get ready to work in a changing, multicultural, and dynamic world, and to adequately answer the challenges of time, the University teacher should be a skilled craftsman and have adequate moral, spiritual, social and educational qualities, possess profound professional knowledge, psychological and pedagogical skills, and have thorough understanding of psychonomic techniques (Table 2).

Table 2. The University Teacher Educational Skills Structure

\begin{tabular}{|c|c|c|c|c|c|}
\hline $\begin{array}{l}\text { Moral and spiritual } \\
\text { qualities }\end{array}$ & $\begin{array}{l}\text { Social and } \\
\text { pedagogical } \\
\text { qualities } \\
\end{array}$ & Professional efficiency & $\begin{array}{l}\text { Psychological } \\
\text { skills }\end{array}$ & $\begin{array}{l}\text { Pedagogical } \\
\text { techniques }\end{array}$ & Psychonomic techniques \\
\hline Humanness & $\begin{array}{l}\text { Organizational } \\
\text { skills }\end{array}$ & $\begin{array}{l}\text { Specialized knowledge } \\
\text { and knowledge of } \\
\text { allied sciences }\end{array}$ & Didactic & $\begin{array}{l}\text { Possessing the skills } \\
\text { of verbal } \\
\text { communication }\end{array}$ & $\begin{array}{l}\text { Ability to take into account the } \\
\text { patterns of the subconscious }\end{array}$ \\
\hline Democracy & Creativity & $\begin{array}{l}\text { Knowledge of } \\
\text { Psychology }\end{array}$ & Communicative & $\begin{array}{l}\text { Possessing the skills } \\
\text { of non-verbal } \\
\text { communication }\end{array}$ & $\begin{array}{l}\text { Ability to influence one's personal } \\
\text { psychophysical condition, resistance } \\
\text { to stress and psychophysical } \\
\text { exhaustion }\end{array}$ \\
\hline Intellectuality & Empathy & $\begin{array}{l}\text { Knowledge of } \\
\text { Pedagogy }\end{array}$ & Constructive & $\begin{array}{l}\text { Pedagogical } \\
\text { tactfulness }\end{array}$ & $\begin{array}{l}\text { Ability to influence other people's } \\
\text { psychophysical condition }\end{array}$ \\
\hline $\begin{array}{l}\text { Being oriented at } \\
\text { positive ideals of } \\
\text { life }\end{array}$ & Attractiveness & $\begin{array}{l}\text { Knowledge of } \\
\text { methodology and } \\
\text { methods of instruction }\end{array}$ & Perceptive & $\begin{array}{l}\text { Ability to control } \\
\text { one's personal } \\
\text { psychophysical } \\
\text { condition }\end{array}$ & $\begin{array}{l}\text { possession of psychotherapeutic } \\
\text { techniques of self-regulation }\end{array}$ \\
\hline Conscienciousness & $\begin{array}{l}\text { Adherence to } \\
\text { principles }\end{array}$ & $\begin{array}{l}\text { Knowledge of } \\
\text { anatomy and } \\
\text { physiology }\end{array}$ & Suggestive & & $\begin{array}{l}\text { Possession of the techniques of the } \\
\text { suggestive-informational influence on } \\
\text { human subliminal mind }\end{array}$ \\
\hline $\begin{array}{l}\text { Honesty and } \\
\text { integrity }\end{array}$ & Strictness & & Cognitive & & $\begin{array}{l}\text { Ability to watch non-verbal and } \\
\text { uncontrolled manifestations of } \\
\text { humans }\end{array}$ \\
\hline Truthfulness & Optimism & & Applied & & \\
\hline Righteousness & Continence & & & & \\
\hline Tolerance & Reflexivity & & & & \\
\hline $\begin{array}{l}\text { Developed sense of } \\
\text { social responsibility } \\
\text { and obligation }\end{array}$ & Observance & & & & \\
\hline
\end{tabular}

A necessary condition for the development of University teachers' pedagogical skills is enriching and expanding their professional and general thesaurus and erudition. The teacher used to be a chief (and often the only) source of information for the student, but now the young draw information from many other sources.

Worldview and philosophical basis of attitude to life and to human is the basis for the University teachers' acquisition of pedagogical skills. There can be no talk of real craftsmanship, if the teacher does not profess humanism and humanness, and if love for man is not a state of mind. One can study and apply a variety of techniques, rules, and methods of teaching, but if the teacher has no internal belief in the value and the nobility of the person being taught, is not concerned with the person and does not empathize for a person's specific life situation and destiny, they are not teachers but average artisans.

This condition is particularly important because previous generations of teachers for the most part were the supporters of the repressive, authoritarian, and inhuman pedagogical paradigm, be it medieval, imperial period or the Soviet totalitarian system. Standing, so to speak, on the shoulders of their predecessors, they themselves are subject to the punitive system of education; modern teachers are hard to overcome inertia, be more flexible, and get rid of old familiar stereotypes.

One of the important conditions for the development of the University teachers' pedagogical skills is a solid philosophical training, extensive knowledge of the strengths and weaknesses of the philosophical concepts, past and present. Particular attention should be paid to the study of humanistic theories. Humanism is the philosophical basis of the new (neoclassical) methodology of pedagogy. This progressive trend is aimed at strengthening the respect for human dignity and human reason as the highest values, at free expression of human feelings and natural abilities, and the human right to earthly happiness.

Modern student-oriented education is based on theoretical principles of humanistic educational thought, the main goal of which is to create such cultural and educational environment which makes possible a free human's choice of the ways of self-actualization. In accordance with the axiological orientations of humanistic education not only a man belongs to the world, depends on it, and manages it, but, and above all, the world belongs to man, and is created by man.

Ideological tenets of humanistic pedagogy are:

- Accepting the person as it is;

- Recognition of the uniqueness and integrity of the individual;

- The person is open to the world;

- The person has certain degrees of freedom from external determination;

- The person is a creative, intentional, and active creature;

- Recognition of the student as an active and enjoying full rights subject of the educational process;

- Denial of the impersonal nature of education;

- An individual approach to the student;

- Natural and cultural orientation as basic principles of education;

- Humanistic-style relations between those who teach and those who learn. 
A thorough acquaintance with the pedagogical works of Socrates, Aristotle, W. Ratke, J.A. Comenius, H. Skovoroda, J. Pestalozzi, K. Ushynskyy, Janusz Korczak, Maria Montessori, V. Sukhomlinsky, S. Amonashvili, and other theorists and practitioners of the human-oriented pedagogy will help teacher in mastering the principles and approaches in humanistic pedagogy.

An important feature of a University teacher is democracy. The principle of democracy requires the recognition of the individual as the ultimate natural and social value. A teacher's democracy first and foremost is their ability of viewing and seeing the student as the subject (and not just the object of) the learning process, a free, self-sufficient person, an equal (by human dimension) partner who deserves respect for their honor and dignity. The teacher recognizes it that the student chooses and creates the needed model of behavior based on their own worldview. The teacher can and must disclose to students a wide range of options in decision-making and behaviors patterns and help navigate which choice is the best, most appropriate, and relevant to the public morality norms. Students take a decision on their own. Meanwhile, the teacher does not have to hide their attitude to the student's choice. Democratic education differs from all the others authoritarian, dogmatic, etc. - in that it is based on the principle of making people be what the nature intended them to. You cannot break a person and impose algorithms of action or lifestyle. The peculiarity of this requirement is the need for a sense of proportion, as the wrong understanding can lead to manifestations of familiarity in dealing with students, which is undesirable and even harmful.

One of the necessary conditions to acquire high-quality pedagogical skills is intellectuality. Being introduced into the public domain in the 60 -ies of the XIX century by the Russian writer P. Boborykin, the term "intellectual" has no clear definition so far. In everyday consciousness an intellectual is a well-read and well-educated person. But it is no secret that, unfortunately, among well-read and welleducated people there are unrefined parasites, envious people, careerists, bribe takers, and rascals. This opinion is confirmed by the English philosopher John Locke: "Teaching sciences promotes integrity in people with good spiritual inclinations, but in people who do not have these traits it only leads to the fact that they are even more stupid and bad".

In this sense an intellectual is a person who certainly adheres to high moral principles, regardless of the circumstances and conditions. Immanent qualities are intellectual humanism and democracy. An intellectual is characterized by the ability to be aware of oneself as a person with pronounced individuality, distinguish one's "I", and the ability to think critically. An intellectual is totally alien to the elements of selfishness, intrigue, aggression, mendacity, dishonesty, and shamelessness. True intellectual is prone to self-irony and irony as a reaction to officialdom (S. Kierkegaard), an intellectual suffers any violence and opposition, or is at least wary of any government.

\subsection{Prerequisites for the University Teachers' Professional and Pedagogical Skills Formation}

In communicating with students the teacher reveals human, political, ethical, cultural, and spiritual sympathies and antipathies, orientation towards some of life's ideals. Ideal is an ethical category, a model that includes sophisticated moral qualities. This is the incarnation of the most valuable and magnificent in person. For a young person an ideal is an example of self-expression and selfimprovement. Student age is characterized by active development of moral and ethical feelings, defining life goals and dominant aspirations, finding role models, and choosing their own social behavior. And at this period the teacher's pronounced life ideals resonate in the students' minds. It is important that these ideals be positive, optimistic, socially significant, patriotic, and based on universal values.

Important factors contributing to the growth and recognition of teachers' pedagogical skills are their integrity, conscientiousness, honesty, truthfulness, fairness, and objectivity. Students are sensitive to the manifestation of these qualities in a teacher and they are the same sensitive to these qualities' weak distinctiveness or absence. Conscience is an ethical category that characterizes the ability to critically evaluate one's actions, behavior, desires, thoughts, and to control one's personal life activity. V. Sukhomlynskyy considered conscience to be a "vigilant guardian of actions and "brain". Integrity is a moral quality of the individual, which is expressed in fidelity to their convictions and responsibilities, conscientious attitude to the assigned work. This category includes honesty, integrity, and openheartedness. Conscientiousness and honesty perform a regulatory function in human behavior, human life, and relationships with others. And as the teacher has to constantly work with young people and all time to be on "the stage of the pedagogical Olympus", behavior control and regulation of their actions should accompany all their activities.

The specificity of a University teacher lies in the necessity to constantly analyze and evaluate students' activities. Young people's senses are rather keen, easily vulnerable, their threshold is too high, and that's why any manifestation of injustice, bias, and dishonesty on the teacher's part meet rejection, resentment, and categorical opposition among students. However, as there are cases of bribery, manipulating with class performance assessments, and extortion, the students' response to teacher's dishonesty is latent in nature. Disregard and contempt for teacher's amorality are not expressed by the students openly or aloud, but such teachers are none the better for it. If positive moral traits are not peculiar to man and are not being cultivated, the person ought to change the profession immediately.

A true teacher is a tolerant person that knows how to display tolerance and respect for students' actions, thoughts, behavior, and beliefs. The criterion for the level of a teacher's tolerance is a student's willingness to freely and unreservedly express their opinions, defend them, and openly argue their views. It must be borne in mind that a 20-year-old person's ability to conscious regulation of one's behavior has not been yet formed. Here lies the explanation of possible fluctuating displays of unmotivated negative behavior, inappropriate actions, and criminal offence of some students. Special attention, care, and support should be given to junior students. Due to the existing gap between school and the university level living and education standards, there takes place a break of habitual patterns. Special research and practical 
experience suggest that mental breakdowns and bad academic performance during the first years at the University are not necessarily related to dishonesty or poor basic knowledge of the student. Failure to assess and monitor themselves and their actions, inability to live without guardianship, the unformed sense of duty and responsibility may be true reasons of behavior deviations.

The teacher should know, understand, and adequately perceive inadequate behavior manifestations of inexperienced students. It would be wise to take precautionary measures and to explain to a young person that lack of control and permissiveness are only illusions; but if a misdemeanor has taken place the student shouldn't become an outcast, the teacher should display understanding, patience, and tolerance, and try to help fix error with minimal loss.

The college age sensitivity promotes active formation and strengthening of such positive personality traits as self-reliance, determination, perseverance, sense of duty, and responsibility. A teacher is an example of this, that's why a well developed sense of obligation and social responsibility are essential features of a true and highly skilled teacher. Being a social quality, responsibility directs the teacher's actions; it is an incentive to selfimprove, a measure of one's professional and social maturity. Responsibility is the foundation of the morals, the core, which underlies all the other qualities of the person.

Democratization and humanization of education are making significant changes in the concept of "responsibility" in terms of its formation. Expanding the boundaries of freedom in the teacher's actions does not yet ensure the development of their social responsibility. In ancient philosophy there were defined two opposing trends in treating the issues of freedom and responsibility - determinism and indeterminism. Deterministic theory argued that the whole course of social development is determined by God, fate. Heraclitus, Bacon, and Descartes associated freedom with the acquisition of the knowledge of the nature laws. In modern philosophy the views on the dialectic of freedom and responsibility as a source of selfidentity prevail. Responsibility primarily comes to light in independent (internally determined) and creative participation in various spheres of life.

The basic condition for the successful formation of a University teacher's sense of obligation and social responsibility are: the formation of their cognitive, volitional, and pertaining of activities responsibility ingredients, the presence of humanistic-oriented social control and objective assessment of their actions and interest of the teacher in one's own work and its results, moral and financial incentives. A sense of obligation and social responsibility is based on a combination of personal qualities and human values, and the ratio of "I - society".

An important prerequisite for the formation of University teachers' professional and pedagogical skills is the availability of the required social and educational skills. It should be borne in mind that these qualities are the result of the influence of the family, educational and institutions, social environment, reference groups and more. The want of the expressed social and educational skills (organizational skills, creativity, empathy, attractiveness, adherence to principles, demands, optimism, chastity, tact, reflexivity, observation, etc.) in the personality prevents the formation of pedagogical skills and becomes a noticeable obstacle to the professional formation of a university teacher. The current teacher cannot confine to the broadcast of information and transfer of knowledge, first and foremost a teacher is an organizer and promoter of cognitive activity, self-study, and scientific creativity of students. Therefore, the presence of organizational skills is a prerequisite for achieving educational excellence.

Organizational skills are a combination of a personality's mental traits that make it possible to successfully and effectively organize work. Organizational skills cover personal orientation (ideological, political, moral, and business) and related traits (sociability, creativity, organization, autonomy, and emotional poise). Possession of the ability to organize people and things helps teachers to effectively manage student groups, create optimal conditions for their operation and development, assist students' public organizations, and conduct a variety of extracurricular activities. Organizational skills include the ability to properly, efficiently and effectively organize their own activities. If such skills have not been developed earlier but the teacher is eager to master the teacher's craft, the teacher should work hard and study the relevant instructional materials and teaching experience of the others, train and practice.

A necessary condition for achieving educational excellence is creativity, a creative potential of people who are engaged in certain types of activity, communication, and thinking. Any educational process is a multicomponent dynamic and changeable phenomenon and receptive approaches do not cover the possibilities of its optimal support. Every segment of the educational process, each of the ordinary or difficult situations requires an original and at the same time effective way of response and it can be provided by a creatively capable specialist.

A necessary social and pedagogical quality for the evolution of educational excellence is the development of empathy, sufficient culture of empathy, that is - the presence of the ability to deeply understand the psychoemotional state, feelings, and experiences of another person, enter the state of another person, empathize, and sympathize with people. Experiencing empathy to the student optimizes their efforts and actions, it supports, encourages, and enhances their academic performance. Empathy is formed by developing knowledge, skills, and beliefs which enable to finely experience another person's mental changes and mentally put oneself in the shoes of another person.

Why are the classes of one teacher eagerly attended and attending the lessons of another teacher becomes an unpleasant duty? The decisive role here is played by the teacher's professional competence, knowledge of the subject and the ability to apply it, etc. However, the human attractiveness of the teacher has a considerable weight, by this we mean the ability to evoke affection, sympathy, and be attractive. This is achieved by understanding the student and their problems, fair, objective attitude, genuine interest in their life and health. The level of general and mental culture, the ability to create a favorable psychological climate around oneself, looks and manners play an exquisite role.

Integrity and rigor to themselves as well as to the students are necessary socio-pedagogical qualities of a 
University teacher. Adherence to principles is a moral and psychological trait that characterizes the legibility of the individual's social position, one's commitment to socially meaningful ideas and beliefs. The teacher is guided in their actions and behavior by universal principles and correct moral convictions; they strictly and consistently adhere to them and defend whether it concerns the teachers themselves or the students.

Teacher's strictness presupposes high moral demands to themselves and students. The level of requirements must be the same. Only in this case, the teacher has the moral right to demand the unconditional fulfillment of their instructions. It is important that requirements, demands and instructions be obviously necessary, intelligible, realistic in terms of performance, and sufficiently clear. A true teacher would not step over the line beyond which the demand turns into tyranny. The requirements are made to student's activities, academic performance, discipline, internal regulations of the institution, moral and ethical standards. But they should not be made to personality traits, qualities and characteristics of the student. The requirement should not touch any personal affairs, issues of honor and dignity. The tone and level of a teacher's rigor are dictated by one's professional training, pedagogical culture, consideration of the situation, circumstances and characteristics of each student. The prerequisite of any educationally expedient demand is respect for who it is directed to. One should always seek the full and timely execution of requirements; otherwise, the requirement as an educational method loses its effectiveness and won't work any longer.

Thus, a demand plays a significant role in the teacher's educational communication with the students. It can be direct and indirect. The immediate, direct requirement is addressed to the student or the group from which the teacher requires some response or action. An indirect claim is directed to a group of students with the expectation that the group transforms and redirects it to the specific student. The requirement may be direct, if the content has a clear indication of a specific action. It must be expressed in the correct, but decisive and persistent form. An indirect requirement is usually expressed in a veiled form and relies on some triggering psychological factors associated with emotions, feelings and experiences of students. There are three groups of indirect requirements: soft, neutral and rigid (Table 3).

Table 3. Types of Indirect Requirements

\begin{tabular}{|c|c|c|}
\hline Soft Requirements & Neutral Requirements & Tough Requirements \\
\hline $\begin{array}{c}\text { Requirement of } \\
\text { Request }\end{array}$ & $\begin{array}{c}\text { Requirement of } \\
\text { Recommendation }\end{array}$ & $\begin{array}{c}\text { Requirement- } \\
\text { Condemnation }\end{array}$ \\
\hline $\begin{array}{c}\text { Confidential } \\
\text { Requirement }\end{array}$ & $\begin{array}{c}\text { Requirement in the form } \\
\text { of a Hint }\end{array}$ & $\begin{array}{c}\text { Requirement- } \\
\text { Distrust }\end{array}$ \\
\hline $\begin{array}{c}\text { Requirement of } \\
\text { Approval }\end{array}$ & Conditional Requirement & $\begin{array}{c}\text { Requirement of } \\
\text { Ultimatum }\end{array}$ \\
\hline
\end{tabular}

Feasibility of using a particular type of requirement depends on the situation and characteristics of the relationship between the students and the teacher.

The requirement in the form of a request is based on mutual respect and trust between teacher and students and successfully works in a stable, established, and wellorganized student group where the sense of obligation and responsibility is developed in the overwhelming majority of its members. This kind of requirements activates internal stimuli of a person to position oneself as a conscientious and socially responsible personality.

The confidential requirement is based on the developed sense of integrity and tender conscience, and stimulates the internal powers of the individuals who realize that they are respected, counted with, and trusted. The individual feels the importance and usefulness of their actions, seeks to justify the trust and improve their positive reputation in the team and in the eyes of the teacher. Fulfilling the requirements of this type as a rule brings satisfaction to the performers themselves.

The requirement in the form of approval is directed at enhancing the motivation for positive action and achieving better performance. This kind of requirements should be applied to junior courses where the students are not sufficiently adapted to their new learning environments and are not always confident in their abilities, accuracy of their actions and objectivity of self-esteem.

The requirement in a form of a recommendation is a tip or a suggestion, calculated on the students' consciousness. In a non-categorical, non-imperative form the student is offered several options for making a decision.

The requirement made as a hint is a form of incentive to action, drawing attention to what is to be done at this point.

A conditional requirement presupposes that the student's interests are the impetus for the activity that is difficult or not interesting at the moment and may be even undesired.

A requirement-condemnation is applied when negative evaluation or condemnation may serve as a psychological brake, a signal to stop or prevent unwanted actions and be an impetus for positive action.

A requirement-distrust is used in cases where the other requirements are not obeyed and when the teacher, knowing the psychological characteristics of students, is confident in the positive outcomes of this very requirement. It can be effective if the student does not care about one's reputation in the eyes of peers and teachers.

A demand in the form of an ultimatum is an extreme demand, and it calls on a thoughtful and cautious use.

In applying these requirements the following rules should be observed:

- No infringing on personal traits, issues, relationships, and secrets of the student;

- Consideration of the individual psychological features of the students pertaining to their age and their marital status;

- No humiliation of the dignity of the student;

- The requirements and demands should be realistic and feasible for implementation;

- The motivation of the requirement should be justified and socially positive.

An excellent teacher is to be proficient in such an effective and powerful tool for identity formation as criticism. Criticism (in Greek kritikz is the ability to distinguish) is a review, discussion, analysis, and evaluation of some object or phenomenon. Criticism in educational work should be based on the principles of humanism and democracy, take into account individual personality characteristics, be positive and of a friendly nature.

The psychologist J. Krasovskii classified criticism and, adapted to the University environment, this classification looks as follows: 
- encouraging criticism;

- reproaching criticism;

- criticism with the elements of analogy;

- criticism filled with hope;

- criticism with praise;

- impersonal criticism ;

- criticism with empathy;

- criticism with sympathy;

- criticism of surprise;

- criticism with irony;

- criticism with complaint;

- criticism with a hint;

- mitigated criticism;

- criticism with rebuke;

- criticism with admonition;

- criticism of claim;

- constructive criticism;

- criticism with the elements of fear.

A skilled master of pedagogical craft should be optimistic, cheerful, confident in their actions, should believe in achieving the set goals and a better future. The philosophy of the optimist is cosmopolitan by its character, it is distinguished by positive attitude to reality, it is not susceptible to feelings of fear and depression. By their buoyant spirit, faith in justice, in the triumph of good principles inductively teachers "infect" students, elevate their spirit, and give the feeling of self-confidence.

A characteristic feature of an excellent teacher is the ability to restrain themselves in any situation. This is achieved by mastering self-control and self-regulation techniques. The teacher should be able to endure too much stress, not to show it to the students, to be quite energetic, mobilized, and self-confident. Restraint allows for an optimal line between tension and relaxation. To achieve full possession of oneself, one's mood, a person can employ mental self-regulation (physical exercises, selfsuggestion, deep concentration, introspection, and other methods). Self-control helps cope with their emotions, feelings, overcome anger, irritation, and achieve confidence in the correctness of their actions.

Reflective abilities are a must in a University teacher's readiness to master the teacher's craft. The specificity of the learning process objectively requires reflexive management. The teacher should be familiar with the psychological characteristics of the student to be able to put oneself in their place, to understand how the student trats the teacher, the material under study, the situation, and to anticipate the reaction to any action. The peculiarity of the reflexive approach lies in the fact that the teacher does not use imperative methods, they instead offer a range of options, give the necessary steering information to make student take an optimal solution. A skilled teacher should be able to penetrate deeply into the inner world and the state of the student, interiorize their peculiarities to choose the best ways of influencing the student's actions and behavior. For successful reflexive management of the educational process the teacher should constantly update and improve their skills and ability, to show emotional sensitivity and psychological insight, empathy, and tact.

Teacher's developed methodological reflection contributes greatly to achieving pedagogical excellence. Moving away from standard, template, and stereotypes, deep insight into the cognitive processes, hard work on expanding the thesaurus, the ability to critically evaluate their activities, targeting students at achieving high academic results are the necessary conditions for University teacher's professional growth.

Civic indifference, high morality and decency, severity and stability of belief, tolerance are important elements of pedagogical reflection. All these qualities and traits are produced and obtained through teacher's daily hard work.

In order to make better and timely decisions, one should be able to accurately and realistically evaluate external information. This is achieved through developing observation. Teacher's observance differs from everyday and routine one by its commitment, ability to "capture" the slightest change in the human psyche that can be hidden, veiled, not intended for the strangers' perception. Any tiniest changes in mood, appearance, actions, and student's reactions serve as the sources of information for a skilled teacher. It is important to learn how to critically and accurately assess the results of observation, given that the peculiarity of perception can be subjective and biased attitude to the subject. Developing external observation, one should "listen" to one's own reflections, to be able to "see" themselves through the eyes of others, look over the side and introspectively. The combination of these qualities contribute to the objectivity of the information perceived, and therefore to more successful and effective educational decision- making.

\section{Conclusion}

Pedagogy of dialogue, partnership, cooperation, and human-orientation puts into the spotlight the interests, needs, and preferences of the student. However, the one who teaches has always been and will stay a key figure in the educational process. Thus, the level of professionalism, education, erudition, mannerliness, and humaneness of the student, and, hence, further moral, cultural, and spiritual progress of the society depend on the professional culture of the teacher, their physical, mental and moral health, and the potential creativity.

\section{References}

[1] Anti-mishmash: Learning to behave politely and to talk properly: Manual, edited by A. Serbenska, Lviv, 1994.

[2] Antonenko-Davydovych, B., The way we speak, 4th ed., Revised and add, Kyiv, 1997.

[3] Carnegie, D., How to gain friends and influence people, Molod, Kyiv, 1990.

[4] Everyday Culture of Speech, Kyiv, 2000.

[5] Goncharenko, S. Ukrainian Pedagogical Dictionary, Lybid, Kyiv, 1997, 376.

[6] Goodman, P., Das VerHangnis Schule, Frankfurt am Main, 1975, 24.

[7] Klimov, K., "On self-organization of children in their activities", Pre-school education, № 12, 33-35, 1979.

[8] Kon, I., Personality Sociology, Politizdat, Moscow, 1967, 383.

[9] Kuzminskyy, A., University Pedagogy: Manual, Znannya, Kyiv, 2005, 486.

[10] Yermolenko, S., Yermolenko, V., Nenets, K., Pustovit, L., New Ukrainian - Russian Dictionary, Dovira, Kyiv, 1996, 797.

[11] Kurlyand, Z., Hmelyuk, R., Semenov, A. et al., Pedagogy of Higher School: Manual : Ed. by Z. Kurlyand, 2nd ed., Revised and add, Znannya, Kyiv, 2005, 399.

[12] Pedagogical skills: Ed. by I. Zyazyun, Higher School, Kyiv, 1997. 
[13] Serbenska, O., Bilous, M., The Ukrainian word's ecology. Vocabulary Directory. The Ukrainian word, Company "Manuscript", Lviv, 2003, 68

[14] Spelling dictionary of the Ukrainian language: Over 125,000 words / Ed. by S. Holovaschuk, M. Peschak, V. Rusanivskyy, O. Taranenko, Dovira, Kyiv, 1999, 989.

[15] Sukhomlinsky, V., Selected Works: Volume 5, Radyanska Shkola, Kyiv, 1977, 494.

[16] Ushinsky, K., Works, Volum 1, Radyanska Shkola, Kyiv, 1952, 134.
[17] Ushinsky, K., "A human as a subject of education", Selected pedagogical works: In 2 Volumes, Vol.1, Radyanska Shkola, Kyiv, 1983, 214.

[18] Yatsenko, T., Active socio- psychological training of teachers for communicating with students: Teachers' Book, Osvita, Kyiv, 1993, 208.

[19] Zyazyun, I., "Spiritual factors of elitist personality", Proceedings of the J. Komenskyy International Slavic Academy of Education, Bendery, № 3, 115-122, 2005. 